\title{
Candidemia from a Urinary Tract Source: Microbiological Aspects and Clinical Significance
}

\author{
B. S. P. Ang, ${ }^{*}$ A. Telenti, B. King, J. M. Steckelberg, and \\ W. R. Wilson
}

\author{
From the Division of Infectious Disease, Department of Medicine, and the \\ Department of Diagnostic Radiology, Mayo Clinic and Mayo \\ Foundation, Rochester, Minnesota; and the Institute for Medical \\ Microbiology, University of Bern, Bern, Switzerland
}

\begin{abstract}
Twenty-six cases of candidemia associated with a well-defined urinary tract source were retrospectively identified and reviewed. Urinary tract abnormalities were present in 23 of 26 patients $(88 \%), 19(73 \%)$ of whom had urinary tract obstruction. Nineteen patients had undergone urinary tract procedures before the onset of candidemia. Episodes of candidemia were brief and low-grade in intensity (median duration, 1 day; median colony count, $1.5 \mathrm{cfu} / 10 \mathrm{~mL}$ of blood). Only eight patients $(31 \%)$ received $\geqslant 500 \mathrm{mg}$ of amphotericin $B$. There were five in-hospital deaths (19\%); two of these deaths were attributed to candidiasis. No late complications of candidemia were documented for the surviving patients. Patients with urologic pathology and candiduria who undergo surgery or manipulation of the urinary tract are at significant risk for candidemia, and further studies should examine the issue of administration of prophylaxis to this group.
\end{abstract}

Candiduria often presents a dilemma to the clinician, as it may represent colonization or infection. The prevalence of candiduria has been estimated at $0.2 \%-6 \%[1,2]$ among asymptomatic volunteers and at $6.5 \%-20 \%$ among hospitalized patients [2, 3]. Despite the high prevalence of candiduria, it is not well known which patients will develop complications such as candidemia. For patients in the critical care setting, the mortality associated with urine cultures positive for Candida species was $50 \%$, as opposed to $19 \%$ for such patients without cultures positive for Candida [4]. On the other hand, Schonebeck and Ansehn [5] observed 40 patients with candiduria that persisted from 1 to 12 months and found that the infection spontaneously resolved in the majority of patients, although five remained candiduric after $>12$ months. The goal of this retrospective study was to describe the characteristics of candidemia arising in patients with a well-defined urinary tract source of infection.

\section{Materials and Methods}

All patients with blood cultures positive for Candida species at the Mayo Clinic from March 1985 to December 1987 were identified through a review of microbiological records. Patients with candidemia were eligible for inclusion in the study if they had concomitant candiduria and no alternative source of candidemia. Candiduria was defined as the pres-

Received 30 December 1992; revised 23 March 1993.

Present address: Department of Medicine III, Singapore General Hospital, Singapore.

Reprints or correspondence: Dr. Brenda Ang, Department of Medicine III, Singapore General Hospital, Singapore.

Clinical Infectious Diseases 1993;17:662-6

(c) 1993 by The University of Chicago. All rights reserved.

$1058-4838 / 93 / 1704-0010 \$ 02.00$ ence of Candida species in urine cultures or the presence of yeast in the urine on microscopy. Recovery of Candida species from skin, sputum, or mucous membranes did not constitute criteria for exclusion. All in-patient and out-patient records were reviewed, and the following data were recorded: age, sex, underlying diseases, potential risk factors, clinical and laboratory features, radiological study findings, pathology reports, and treatment and outcome. Blood cultures were done for patients if they had fever or if the clinical circumstances suggested the possibility of systemic infection.

The onset of fungemia was defined as the first day on which blood cultures positive for Candida were obtained. Potential risk factors were defined as: (1) administration of antimicrobial therapy for at least 1 week before the onset of fungemia; (2) administration of corticosteroid therapy at the equivalent of $15 \mathrm{mg}$ of prednisolone daily for at least 1 week; (3) administration of cytotoxic therapy; and (4) manipulation of the urinary tract within 2 weeks of the onset of fungemia.

Urologic procedures include open surgery, nephrostomies, cystoscopies, stent placements, intermittent urinary catheterizations, and placement of an indwelling urinary catheter. Clinical features that were recorded included fever (temperature $>38.0^{\circ} \mathrm{C}$ ) at the onset of candidemia and evidence of dissemination of candidal infection to other organs. Laboratory features reviewed included leucocyte counts and serum creatinine levels; radiological study findings were also reviewed.

Microbiological studies. Quantitative blood cultures were performed according to previously described methods [6]. Thirty milliliters of blood were drawn for each culture, and $10 \mathrm{~mL}$ each were inoculated into an Isolator tube (DuPont, Wilmington, DE), a Septi-chek bottle (Roche Diagnostic Systems, Nutley, NJ), and a nonvented bottle containing trypticase soy broth. Aliquots from the Isolator tube were 
inoculated onto the surface of sheep-blood and chocolate agar plates incubated under $5 \% \mathrm{CO}_{2}$ for 7 days at $35^{\circ} \mathrm{C}$. The remainder of the sediment was inoculated onto the surface of Sabouraud dextrose, inhibitory-mold, and brain-heart infusion agar plates, which were incubated for 3 weeks at $30^{\circ} \mathrm{C}$. Plates were inspected daily. Identification of Candida species was done using the API yeast identification system (Plainview, NY). Colony counts (cfus $/ 10 \mathrm{~mL}$ of blood) were determined on the first day the blood cultures became positive by counting all colonies of Candida on media plated with blood from the Isolator tube. If more than one set of blood cultures was positive, the colony count was divided by the number of sets of cultures. If the Isolator tube inoculum was negative and that in the Septi-chek bottle positive, the colony count was recorded as zero. The duration of candidemia was defined as the number of days from the first finding of a positive blood culture up to and including the last day blood cultures remained positive.

\section{Results}

Of the 249 patients with candidemia who were identified during the study period, $26(10.4 \%)$ had infection associated with candiduria and fulfilled our criteria for inclusion in this study (table 1). Twelve patients were male, and 14 were female. Their ages ranged from 16 years to 83 years (mean, 59.3 years; median, 67 years). Malignant disorders were present in 19 (73\%) of 26 patients; 17 of these patients had direct primary or metastatic involvement of the urinary tract. Three patients (12\%) had received solid organ transplants, three had nonmalignant urologic conditions (one patient each had a stone at the ureteropelvic junction, eosinophilic cystitis, and neurogenic bladder), and one had ulcerative colitis. Two of 26 patients (8\%) were also diabetic. Twenty-two patients $(85 \%)$ had received at least a 1-week course of antibiotics. Seven patients (27\%) had received either steroids, cytotoxic agents, or both. None of the patients were neutropenic prior to onset of candidemia.

Structural abnormalities of the urinary tract were present in 23 patients (88\%). Nineteen patients (73\%) had evidence of obstruction. Ileal or colonic conduits were present in six of these 19 patients. Nineteen patients $(73 \%)$ had undergone instrumentation or open surgery involving the urinary tract within 2 weeks before the blood cultures were found to be positive; of these, three had had only indwelling catheters inserted. The remaining seven patients had undergone urologic procedures $>2$ weeks before documentation of candidemia.

Candiduria was documented to be present at the time of procedures for 17 patients. For two other patients, candiduria had been documented to be present $>1$ week before the procedure. Four patients were noted to have candiduria after a procedure; subsequently, cultures of blood from these patients were positive for Candida species. The interval be- tween the most-recent procedure and onset of candidemia ranged from $<1$ day to 10 days (mean, 3.8 days; median, 3 days); three patients became febrile and candidemic within 24 hours after a procedure was performed.

Fever was documented in 24 patients (92\%). Blood cultures were done for the remaining two patients because radiological findings suggested abscess formation in one, and persistently positive urine cultures, pyuria, leukocytosis, and flank pain were documented for the other. Nine (38\%) of 24 patients had leukocytosis, with leukocyte counts of $>12,000 / \mathrm{mm}^{3}$. The serum creatinine level was increased $(>1.2 \mathrm{mg} / \mathrm{dL})$ in 14 patients at the time of admission to the hospital and in 21 patients at the time of candidemia. No abnormalities suggestive of disseminated candidiasis were found on ophthalmologic examination of 16 patients or in four patients who underwent transthoracic echocardiography.

Microbiological results. Blood cultures yielded Candida albicans for 19 patients (73\%); Torulopsis glabrata for five patients (19\%); and Candida tropicalis, Candida parapsilosis, and an unidentified Candida species for three patients (8\%). For one patient, blood culture yielded both $C$. albicans and $T$. glabrata. For 21 patients, the fungus in urine was identified to the species level, and the isolates all corresponded to the blood isolates, including those from the patient with polymicrobial candidemia.

The colony count, as assessed using the Isolator tube, ranged from $1 \mathrm{cfu}$ to $54.5 \mathrm{cfu} / 10 \mathrm{~mL}$ of blood, with a median count of $1.5 \mathrm{cfu} / 10 \mathrm{~mL}$ of blood. For two patients, cultures performed with use of the Isolator tube were negative; only those performed with the Roche bottle were positive. Twenty-one patients ( $85 \%$ ) had counts less than or equal to 5 $\mathrm{cfu} / 10 \mathrm{~mL}$ of blood.

The number of sets of blood cultures done ranged from 2 to 24 (median, 12 sets; mean, 12.6 sets). The number of days over which cultures were done ranged from 1 to 13 days (median, 6 days; mean, 6.2 days). Twenty-one patients had follow-up blood cultures that were documented to be negative. One patient had positive blood cultures on 3 consecutive days and died on the fourth day, probably still candidemic. The remaining four patients were febrile at the onset of candidemia; however, their symptoms resolved, and repeated cultures were not performed.

The duration of candidemia ranged from 1 to 12 days, with 15 patients having candidemia for 1 day. The median duration of candidemia for all patients was 1 day. The patient with the longest duration of candidemia (case 10) had an obstruction of the urinary tract that required repeated procedures, and his urine cultures remained positive.

Radiological findings. Findings on radiological studies of the urinary tract done immediately before and after episodes of candidemia were reviewed. These studies included ultrasonography, computerized tomography, and antegrade or intravenous pyelography. Nineteen patients had evidence of hy- 
Table 1. Summary of clinical features, microbiological aspects, treatment, and outcome for 26 patients with candidemia and candiduria.

\begin{tabular}{|c|c|c|c|c|c|c|c|c|c|}
\hline \multirow[b]{2}{*}{$\begin{array}{l}\text { Case } \\
\text { no. }\end{array}$} & \multirow[b]{2}{*}{ Age/sex } & \multirow[b]{2}{*}{$\begin{array}{l}\text { Underlying } \\
\text { condition }\end{array}$} & \multirow[b]{2}{*}{$\begin{array}{l}\text { Urinary tract } \\
\text { obstruction }\end{array}$} & \multirow[b]{2}{*}{$\begin{array}{l}\text { Urologic } \\
\text { procedure }\end{array}$} & \multicolumn{2}{|c|}{ Candidemia } & \multirow[b]{2}{*}{$\begin{array}{c}\text { Renal } \\
\text { involvement }\end{array}$} & \multirow[b]{2}{*}{$\begin{array}{l}\text { Amphotericin B } \\
\text { (total dose) }\end{array}$} & \multirow{2}{*}{$\begin{array}{c}\text { Outcome (duration of } \\
\text { follow-up or cause of } \\
\text { death) }\end{array}$} \\
\hline & & & & & $\begin{array}{l}\text { Duration } \\
\text { (d) }\end{array}$ & $\begin{array}{c}\text { Counts } \\
(\mathrm{cfu} / 10 \mathrm{~mL})\end{array}$ & & & \\
\hline 1 & $61 / \mathrm{M}$ & CA. colon & Bilateral & Nephrostomy & 1 & 1 & Proven & $1.0 \mathrm{~g}$ & Died (4 mo) \\
\hline 2 & $78 / \mathrm{M}$ & $\begin{array}{l}\text { Benign } \\
\text { prostatic } \\
\text { hypertrophy, } \\
\text { ureteric } \\
\text { stone }\end{array}$ & Unilateral & $\ldots+$ & 6 & 3 & ND & $0.5 \mathrm{~g}$ & Alive (22 mo) \\
\hline 3 & $83 / \mathrm{F}$ & CA, bladder & Bilateral & Nephrostomles & 1 & l & ND & None & Died $(21 \mathrm{mo})$ \\
\hline 4 & $70 / \mathrm{M}$ & CA. bladder & Unilateral & Stents & 1 & 7 & Proven & $0.05 \mathrm{~g}$ & Alive (1 mo) \\
\hline 5 & $67 / F$ & CA. bladder & Bilateral & $\begin{array}{l}\text { Cystoscopy, } \\
\text { cystectomy }\end{array}$ & 5 & 5 & Possible & $1.5 \mathrm{~g}$ & Alive (1 mo) \\
\hline 6 & $67 / F$ & CA, rectum & Bilateral & UC alone & $1^{*}$ & 2 & ND & None & Died (14 mo) \\
\hline 7 & $68 / \mathrm{M}$ & CA. tongue & None & UC alone & 1 & 2 & Possible & $1.0 \mathrm{~g}$ & $\operatorname{Died}(2 \mathrm{mo})$ \\
\hline 8 & $67 / \mathrm{M}$ & CA, kidney & None & $\ldots{ }^{\dagger}$ & $3^{*}$ & 54.5 & Proven & $0.02 \mathrm{~g}$ & $\begin{array}{l}\text { Died in hospital } \\
\text { (candidiasis was } \\
\text { contributing factor) }\end{array}$ \\
\hline 9 & $53 / \mathrm{M}$ & CA, pancreas & Unilateral & Stents & 8 & 11 & ND & $0.5 \mathrm{~g}$ & $\operatorname{Died}(6 \mathrm{mo})$ \\
\hline 10 & $68 / \mathrm{M}$ & CA, bladder & Unilateral & $\begin{array}{l}\text { Nephrostomy, stents, } \\
\text { cystoprostatectomy }\end{array}$ & 12 & 1 & Possible & $0.25 \mathrm{~g}$ & Alive ( $11 \mathrm{mo}$ ) \\
\hline 11 & $36 / F$ & $\begin{array}{l}\text { Eosinophilic } \\
\text { cystitis }\end{array}$ & None & $\begin{array}{l}\text { Intermittent } \\
\text { catheterization }\end{array}$ & 7 & 16 & ND & $0.4 \mathrm{~g}$ & Alive (10 mo) \\
\hline 12 & $70 / \mathrm{F}$ & CA, breast & Bilateral & $\ldots+$ & 6 & 1 & Proven & $0.35 \mathrm{~g}$ & Died ( 9 mo) \\
\hline 13 & $66 / M$ & CA, pancreas & None & UC alone & 1 & 18.5 & ND & None & Alive (I mo) \\
\hline 14 & $34 / F$ & CA. ovary & Unilateral & Stents & 1 & 1 & ND & $0.5 \mathrm{~g}$ & Died (2 mo) \\
\hline 15 & $64 / F$ & CA, breast & Unilateral & Nephrostomy, stents & 1 & 0 & ND & None & $\begin{array}{l}\text { Died in hospital } \\
\text { (pulmonary embolism) }\end{array}$ \\
\hline 16 & $26 / \mathrm{F}$ & $\begin{array}{l}\text { Renal } \\
\text { transplant }\end{array}$ & None & $\begin{array}{l}\text { Antegrade } \\
\text { pyelogram, } \\
\text { cystoscopy }\end{array}$ & 5 & 3 & Proven & $0.5 \mathrm{~g}$ & $\begin{array}{l}\text { Transplant nephrectomy; } \\
\text { alive (l y) }\end{array}$ \\
\hline 17 & $16 / \mathrm{F}$ & $\begin{array}{c}\text { Neurogenic } \\
\text { bladder }\end{array}$ & Bilateral & $\begin{array}{l}\text { Nephrostogram, } \\
\text { colonic conduit }\end{array}$ & 1 & 5 & ND & None & Alive $(43 \mathrm{mo})$ \\
\hline 18 & $28 / \mathrm{M}$ & $\begin{array}{l}\text { Ulcerative } \\
\text { colitis }\end{array}$ & None & $\ldots+$ & 1 & 1 & ND & None & Alive (1 mo) \\
\hline 19 & $63 / \mathrm{F}$ & CA, bladder & Bilateral & Stents, cystectomy & 2 & 2 & $\mathrm{ND}$ & $0.2 \mathrm{~g}$ & Alive (36 mo) \\
\hline 20 & $79 / \mathrm{M}$ & CA. bladder & Unilateral & Stents, cystectomy & 1 & 2 & Possible & None & Alive $(4 y)$ \\
\hline 21 & $68 / \mathrm{M}$ & CA, rectum & Bilateral & Nephrostomy & 1 & 1 & ND & None & $\begin{array}{l}\text { Candidemia recurred; } \\
\text { died }(3 \mathrm{y})\end{array}$ \\
\hline 22 & $78 / \mathrm{F}$ & Lymphoma & Bilateral & $\begin{array}{l}\text { Stent, nephrostomies, } \\
\text { cystoscopy }\end{array}$ & 1 & 0 & Possible & $0.05 \mathrm{~g}$ & $\begin{array}{l}\text { Died in hospital } \\
\text { (lymphoma) }\end{array}$ \\
\hline 23 & $25 / \mathrm{M}$ & $\begin{array}{l}\text { Liver } \\
\text { transplant }\end{array}$ & Unilateral & $\begin{array}{l}\text { Stent, cystoscopy, } \\
\text { ureteric } \\
\text { anastomosis }\end{array}$ & 1 & 1 & Proven & $0.08 \mathrm{~g}$ & $\begin{array}{l}\text { Died in hospital } \\
\text { (candidiasis and liver } \\
\text { failure at autopsy) }\end{array}$ \\
\hline 24 & $68 / \mathrm{F}$ & Lymphoma & Bilateral & $\ldots+$ & 5 & l & ND & $1.0 \mathrm{~g}$ & $\begin{array}{l}\text { Died in hospital } \\
\text { (lymphoma) }\end{array}$ \\
\hline 25 & 79/M & CA, prostate & Unilateral & $\ldots+$ & $2^{*}$ & 1 & Possible & $0.5 \mathrm{~g}$ & Alive (46 mo) \\
\hline 26 & $33 / F$ & $\begin{array}{l}\text { Renal } \\
\text { transplant }\end{array}$ & None & $\ldots+$ & 1 & 1 & ND & $0.2 \mathrm{~g}$ & Alive (52 mo) \\
\hline
\end{tabular}

NOTE. $\quad \mathrm{CA}=$ cancer; proven $=$ renal involvement documented on microbiology or histology; $\mathrm{ND}=$ not documented; possible $=$ renal involvement suggested by radiological study results; $\mathrm{UC}=$ urinary catheterization.

${ }^{*}$ Cultures not repeated.

${ }^{\dagger}$ Procedures were performed $>2$ weeks before onset of candidemia.

dronephrosis; two patients had debris in their collecting systems of indeterminate etiology. One patient had findings strongly suggestive of an abscess in the lower pole of the kidney, while three had abnormal collections of fluid in the perinephric space. Changes suggestive of renal parenchymal disease were observed for four other patients. Precise delineation of parenchymal involvement was hampered by the inability to administer contrast agents to many patients with poor renal function.

Percutaneous aspiration of renal tissue or perinephric fluid was done for five patients, and Candida species were cultured from all of the specimens. For three patients the investigations were done while they had candidemia; for the other two patients, aspiration was done 3 days after candidemia 
resolved in case 1 and 2 months before it developed in case 8. Carcinoma of the kidney recurred in case 8 and was complicated by the formation of an abscess, which was subsequently drained surgically. For one additional patient (case 23), Candida grew from renal tissue obtained at autopsy, 9 days after an episode of candidemia that lasted 1 day; urine cultures had previously been positive for Candida species on 9 different days before the development of candidemia.

Treatment and outcome. Eighteen patients (69\%) received amphotericin B for treatment of candidemia. Eight ( $31 \%$ ) of 26 patients received $>500 \mathrm{mg}$ of amphotericin B; one patient in this group died of the primary disease (lymphoma). The remaining seven patients were observed for periods ranging from 1 to 22 months after the onset of candidemia (mean, 8 months; median, 2 months). Among the 10 patients who received amphotericin $B$ in total doses of $<500$ $\mathrm{mg}$, there were three deaths before completion of amphotericin therapy. Candidiasis was thought to be a contributing cause of death for one patient because he remained candidemic until his death, while disseminated candidiasis was documented at autopsy in another. The remaining seven patients received a median total dose of $200 \mathrm{mg}$ of amphotericin B; this group included one patient who received $56 \mathrm{mg}$ of amphotericin B followed by a 2-month course of oral ketoconazole (400 mg daily). These patients did not receive additional antifungal therapy and were followed for periods ranging from 1 to 52 months (mean, 23 months; median, 11 months); no evidence of candidiasis was observed.

Among the remaining eight patients who received no antifungal therapy for candidemia, there was one death due to recurrent pulmonary embolism. The remaining seven patients were followed for periods ranging from 1 to 57 months (mean, 23 months; median, 14 months). One patient (case 21 ) continued to have candiduria and urinary tract obstruction requiring repeated procedures and had reinfection of his bloodstream with the same species of Candida 8 months after the first episode.

Overall, there were five in-hospital deaths, giving a mortality of $19 \%$ in this patient population. Two deaths $(8 \%)$ were directly attributed to candidiasis.

\section{Discussion}

The prevalence of candiduria among hospitalized patients has been estimated to range from 6.5\% [3] to 20\% [2]. Despite this prevalence candidemia from a urinary tract source seems to be a relatively rare complication, since a prospective study of 28 patients with candiduria identified only one patient (3.6\%) who developed candidemia [7]. In our study of 249 consecutive cases of candidemia, a definite urinary source was identified in 26 patients $(10.4 \%)$; this figure is in agreement with those of Dyess et al. [8], who identified the urinary tract as the probable source of candidemia in nine of 83 patients $(10.8 \%)$. Our estimate is probably conservative, as those cases with other potential sources of infection were excluded.

Patients with candidemia from a urinary source had a characteristic profile: most had significant anatomical urinary-tract pathology that was frequently complicated by obstruction, and these patients were subject to urological procedures such as stenting, insertion of nephrostomy tubes, or major urinary tract surgery.

In contrast to candidemia that arises from an intravascular focus [9], episodes of candiduria-associated candidemia were low-grade and of a short duration, and in many cases resolved spontaneously prior to the institution of specific antifungal therapy. Three patients became candidemic within 24 hours after a procedure; however, candidemia in most patients did not occur immediately after manipulation, but several days later. A plausible explanation for this course of events includes the following factors: (1) an ascending infection facilitated by urinary manipulation in the presence of candiduria; (2) subsequent development of micro- or macrofoci of renal parenchymal infection; and (3) limited or transient low-grade candidemia, perhaps precipitated by additional insults. Alternatively, in some instances candidemia may have occurred spontaneously and coincidentally with urinary tract manipulation.

Only eight patients received a cumulative dose of $>500$ mg of amphotericin B. One patient in this group died while receiving therapy, presumably of lymphoma, as there was no evidence of residual infection with Candida. Among the 18 patients who received no antifungal therapy or received a cumulative dose of $<500 \mathrm{mg}$ of amphotericin $\mathrm{B}$, there were four in-hospital deaths. Disseminated candidiasis was documented at autopsy in one patient, and candidiasis was thought to be a contributing cause of death for another patient.

The mortality rate in this series is lower than that reported in studies of other patient populations with candidemia (e.g., $38 \%$ among surgical patients [10] and $70 \%$ among immunosuppressed patients [ 111$]$ ). Lower mortality may be related to the transient duration of candidemia and the low colony counts. The duration of candidemia has been identified as a risk factor for tissue invasion in marrow transplant recipients [12]. Although quantitative colony counts have been found to correlate with the clinical course of bacteremic patients [13], a similar association was not observed for candidemia in one study [14].

Optimal antifungal therapy for candidemia has not been established. Initial treatment with amphotericin B is usually advised [15], but optimal duration of therapy is controversial [16], particularly when infection is not associated with a removable source such as an intravenous catheter. Solomkin et al. [17] suggest that a total dose of $6 \mathrm{mg}-8 \mathrm{mg} / \mathrm{kg}$ may be sufficient to clear fungemia in postsurgical patients [17]. Ex- 
perience with the new imidazole drugs for treatment of systemic candidiasis and candidemia is limited [18, 19].

Our retrospective experience does not provide a basis for making specific treatment recommendations. However, the documentation of an association between renal parenchymal infection and Candida-related mortality suggests the need for specific treatment with antifungal agents despite the apparent transient nature of the episodes of candidemia.

\section{Acknowledgments}

The authors wish to acknowledge the assistance of T. F. Smith, Ph.D., Director, Section of Clinical Microbiology, G. D. Roberts, Ph.D., Head of Mycology, and the staff of the Clinical Microbiology Laboratory, Department of Pathology and Laboratory Medicine, Mayo Clinic.

\section{References}

1. Seneca $\mathbf{H}$, Peer P. Clinical laboratory diagnosis of urinary tract infections. J Urol 1965;94:78-81.

2. Goldberg PK, Kozinn PJ, Wise GJ, Nouri N, Brooks RB. Incidence and significance of candiduria. JAMA 1979;241:582-4.

3. Umenai T, Ishida N. The significance of candiduria. Tohoku J Exp Med 1977;122:59-63.

4. Neumann PR, Rakower SR. The significance of positive cultures for Candida in the critically ill patient. Crit Care Med 1978;6:73-6.

5. Schonebeck J, Ansehn $S$. The occurrence of yeast-like fungi in the urine under normal conditions and in various types of urinary tract pathology. Scand J Urol Nephrol 1972;6:123-8.

6. Henry NK, McLimans CA, Wright AJ, Thompson RL, Wilson WR, Washington JA II. Microbiological and clinical evaluation of the Isolator lysis-centrifugation blood culture tube. J Clin Microbiol $1983 ; 17: 864-9$.

7. Rivett AG, Perry JA, Cohen J. Urinary candidiasis: a prospective study in hospital patients. Urol Res 1986;14:183-6.
8. Dyess DL, Garrison RN, Fry DE. Candida sepsis: implications of polymicrobial blood-borne infection. Arch Surg 1985;120:345-8.

9. Telenti A, Steckelberg JM, Stockman L, Edson RS, Roberts GD. Quantitative blood cultures in candidemia. Mayo Clin Proc 1991;66: 1120-3.

10. Burchard KW, Minor LB, Slotman GJ, Gann DS. Fungal sepsis in surgical patients. Arch Surg 1983;118:217-21.

11. Young RC, Bennett JE, Geelhoed GW, Levine AS. Fungemia with compromised host resistance: a study of 70 cases. Ann Intern Med 1974;80:605-12.

12. Goodrich JM, Reed EC, Mori M, et al. Clinical features and analysis of risk factors for invasive candidal infection after marrow transplantation. J Infect Dis 1991;164:731-40.

13. Whimbey E, Wong B, Kiehn TE, Armstrong D. Clinical correlations of serial quantitative blood cultures determined by lysis-centrifugation in patients with persistent septicemia. J Clin Microbiol 1984; 19: 766-71.

14. Whimbey E, Kiehn TE, Brannon P, Blevins A, Armstrong D. Quantitative blood cultures in immunocompromised patients with candidemia (abstract 1349). In: Program and abstracts of the 27th Interscience Conference on Antimicrobial Agents and Chemotherapy. Washington, DC: American Society for Microbiology, 1987.

15. Komshian SV, Uwaydah AK, Sobel JD, Crane LR. Fungemia caused by Candida species and Torulopsis glabrata in the hospitalized patient: frequency, characteristics, and evaluation of factors influencing outcome. Rev Infect Dis 1989;1 1:379-90.

16. Medoff, G. Controversial areas in antifungal chemotherapy: shortcourse and combination therapy with amphotericin B. Rev Infect Dis 1987;9:403-7.

17. Solomkin JS, Flohr A, Simmons RL. Candida infections in surgical patients: dose requirements and toxicity of amphotericin B. Ann Surg 1982;195:177-85.

18. Robinson PA, Knirsch AK, Joseph JA. Fluconazole for life-threatening fungal infections in patients who cannot be treated with conventional antifungal agents. Rev Infect Dis 1990;12(suppl 3):S349-63.

19. Tricot G, Joosten E, Boogaerts MA, Van de Pine J, Cauwenbergh G. Ketoconazole vs. itraconazole for antifungal prophylaxis in patients with severe granulocytopenia: preliminary results of two nonrandomized studies. Rev Infect Dis 1987;(suppl 1):S94-9. 